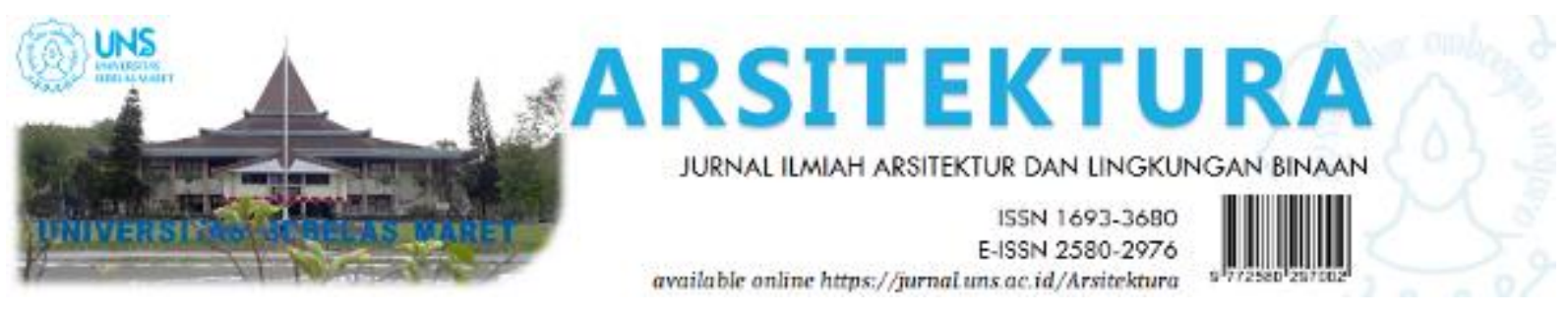

Volume 19 Issue 1 April 2021, pages:13-24

\title{
Elemen Arsitektur Pembentuk Karakter Bangunan pada Tapak Warisan Dunia Kota Sawahlunto Sumatera Barat, Indonesia
}

\section{The Architecture Element of Heritage Buiding in Sawahlunto World Heritage Site West Sumatra, Indonesia}

\author{
Rika Cheris ${ }^{1 *}$, Imbardi $^{2 *}$, Lalu Muhammad Ivan ${ }^{3 *}$ \\ Prodi Arsitektur, Fa kultas Teknik, Universitas Lancang Kuning ${ }^{1 *}$ \\ rika.cherish@unilak.ac.id \\ Prodi Arsitektur, Fakultas Teknik, Universitas Lancang Kuning ${ }^{2 *}$ \\ Prodi Arsitektur, Fakultas Teknik, Universitas Lancang Kuning ${ }^{3 *}$
}

DOI: https://doi.org/10.20961/arst.v19i1.47961

Received: January 22,2021 Revised: February 8,2021 Accepted: March 10,2021 Available online: April 30,2021

\begin{abstract}
The mining industrial city of Sawahlunto has been designated as a World Heritage Site recognized by UNESCO in 2019. The designation of this building has been through a study of its form, function, ownership and area. However, urban development will still occur. This is of course caused by several factors. Chang es in the city, the design and function of the se buildings need to be controlled to keep cultural heritag e buildings from being lost. For this reason, research is needed to determine the character-forming elements of cultural heritage building sin Sawahlunto City. This will be very useful for the Government to make guidelines for the restoration of cultural heritage buildings. The research method used is qualitative descriptive analysis with the UNESCO attribute building sample method that willbe selected in each area. For this initial stage, the sample to be taken is in the core area (Map of Land Ownership Area A, Sawahlunto Mining and company town: A5 company town, Nominated Property) in the Ombilin Sawahlunto mining worldheritage site, We st Sumatra. The sample will become a guideline for similar buildings, then will become a reference for any conservation.
\end{abstract}

Keywords: architecture element; building character; mining town Sawahlunto

\section{PENDAHULUAN}

Kota Sawahlunto telah ditetapkan menjadi Tapak Warisan Dunia oleh UNESCO pada tanggal 10 Juli 2019 dalam Convention Concerning The Protection of The World Cultural and Natural Heritage di Azerbajian.
The World Heritage Committee has inscribe Ombilin Coal Mining Heritage of Sawahlunto menjadi salah satu Tapak Warisan Dunia. Anugrah ini adalah sebagai bukti atas terpeliharanya seluruh asset tambang barubara ombilin yang sangat berjaya pada masa 
kolonial dan menggerakkan 3 pilar ekonomi yang cukup besar pada masanya, yaitu dibangunnya rel kereta api yang menghubungkan langsung ke pelabuhan Teluk Bayur di Kota Padang, dibangun pabrik semen Indarung dan dibangunnya Pelabuhan Teluk Bayur sebagai pusat transportasi yang cukup besar di Pesisir Pulau Sumatra bagian Tengah. Ketiga proyek besar ini dibangun dari akhir abad 19 dan selesai pada awal abad 20.

Mega proyek tambang batu bara Ombilin telah mampu mengubah secara luar biasa daerah pedalaman di lembah yang sempit, terkurung perbukitan hingga wilayahnya bagaikan "penjara alam" di pedalaman Minangkabau. Di dasar cekungan lembah sempit, yang dibelah dua anak sungai itulah didirikan dan dibangun berbagai sarana dan prasarana pertambangan lengkap dengan fasilitas pendukungnya (Gino, 2019).Berdasarkan dokumen foto yang di temukan pembangunan awal di Kota ini sebagai dukungan terhadap aktifitas tambang batubara yaitu penjara orang rantai (buruh tambang) dan rumah pekerja tambang. (Cheris, 2009a) terlihat pada gambar 01 .

Seiring dengan berjalannya waktu, deposit batubara mengalami defisit akibat kebutuhan dunia industri. Kenyataan ini mengharuskan Pemerintah Kota mencari alternative sumber devisa selain tambang batu bara. Pada tahun 2002 Kota Sawahlunto akhirnya mendeklarasikan visi kota yaitu Kota wisata Tambang yang berbudaya pada tahun 2020 . Cita-cita ini dicetuskan oleh karena kota kecil ini harus keluar dari keterbatasan produksi Tambang batubara. Visi sebagai Kota Wisata Tambang memang lebih cocok untuk kota ini, dikarenakan potensi warisan budaya yang mereka miliki cukup besar. Setelah pencanangan tersebut, Pemerintah Kota mulai melakukan pembenahan terhadap seluruh fasilitas sarana prasarana serta infrastruktur bekas tambang yang memungkin untuk dilakukan perubahan serta adative-reuse. Perubahan yang telah dilakukan terutama pada bangunan-bangunan peninggalan tambang ini dilakukan melalui penyesuaian antara disain dan fungsi atau yang disebut teori Form Follow Function (LESLIE, 2010). Beberapa pekerjaan adaptive re-use yang teah dilaksanakan seperti Museum, Gallery, kantor perusahan tambang, kantor dinas Pariwisata, sekolah, rumah dinas dokter, rumah pejabat
Pemerintah eselon 2 dan eselon 3. Sedangkan perubahan fungsi perumahan masyarakat dilakukan dengan cara memberi subsidi kepada masyarakat sehingga bisa memperbaiki rumah mereka sendiri. Perubahan fungsi ini juga mengalami beberapa masalah dalam mempertahankan bangunan lama (heritage) disebabkan belum adanya aturan yang mengikat masyarakat ketika akan melakukan perubahan. Peruntukkan kawasan pada daerah permukiman menjadi sesuatu karakteristik unik karena bentuk dan desain bangunan yang serba terbatas. Sarana dan utilitas perumahan dahulunya dibuat secara massal karena terbatasnya ruang (Cheris, 2014). Sehingga fungsi harus menyesuaikan dengan bentuk fisik yang ada.

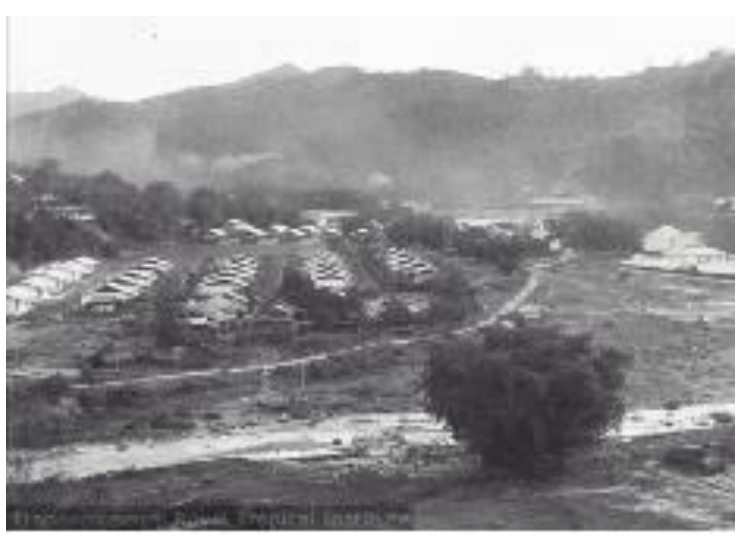

Gambar 1. Sa wahlunto pada awal abad 20 Sumber:Tropenmuseum Royal Tropical Institute.

Penyesuaian fungsi juga seringkali menganggu terhadap arsitektur bangunan, terutama bentuk depan (fasàde). Hal ini terjadi biasanya disebabkan oleh beberapa hal, seperti bahan material yang sudah tidak tersedia lagi, juga keinginan pemilik yang menginginkan hal-hal yang baru pada rumah mereka. Perubahan yang sangat signifikan biasanya terjadi pada bentuk jendela, pintu dan ventilasi. Ketiga elemen utama bangunan tersebut lebih rentan mengalami kerusakan, sehingga diperlukan perbaikan. Perubahan yang tidak terkndali ini akan menghilangkan image arsitektur secara keseluruhan pada bangunan tersebut. Elemen arsitektur tersebut dapat digunakan untuk mengidentifikasi tipologi dari suatu bangunan dengan mengklasifikasi kesamaan bentuk, struktur, dan karakter dari bangunan (Yetti, 2020). Banyak sekali ditemukan pada kota ini 
kesamaan bentuk elemen arsitektur. Sehingga pertanyaannya adalah bagaimana menemukan elemen-elemen arsitektur sebagai pembentuk karakter bangunan warisan tambang di kota Sawahlunto yang akan tetap digunakan oleh masyarakat kota sehingga image kota tidak berubah akibat adanya perubahan fungsi (adaptive-reuse). Hasil dari riset ini merupakan sebuah dokumentasi dari elemen arsitektur akan sangat bermanfaat untuk pembuatan acuan pemugaran bangunan pelestarian pada kota Sawahlunto nantinya.

\section{METODE}

Pada riset kali ini akan menggunakan metode penelitian kualitatif deskriptif analisis. Pendekatan yang dilakukan yaitu terhadap pengambilan sampel beberapa bangunan yang mewakili gaya-gaya arsitektur pada masanya. Observasi dan pengambilan data dilakukan secara langsung di kota Sawahlunto Provinsi Sumatera Barat yang berjarak sekitar $278 \mathrm{~km}$ dari Kota Pekanbaru. Riset ini merupakan lanjutan dari riset Sustainable Conservation of the Coal Mining Town: Ombilin Sawahlunto West Sumatra Indonesia Contex (Cheris, 2020). Proses riset selanjutnya akan dilakukan pengukuran dan pengambaran serta diskusi dilakukan bersama-sama dengan tim pendamping guna menyamakan data dan mengetahui perubahan yang telah terjadi. Kemudian membantu memberi masukan untuk program-program Pemerintah dimasa yang akan datang berkenaan dengan telah ditetapkannya Kota ini sebagai salah satu tapak warisan dunia oleh UNESCO.

\section{HASIL DAN PEMBAHASAN}

Tipologi adalah suatu studi yang berkaitan dengan tipe dari beberapa objek yang memiliki jenis yang sama. Tipologi merupakan sebuah bidang studi yang mengklasifikasikan, mengkelaskan, mengelompokkan objek dengan ciri khas struktur formal yang sama dan kesamaan sifat dasar ke dalam tipe-tipe tertentu dengan cara memilah bentuk keragaman dan kesamaan jenis. Aspek klasifikasi dalam pengenalan tipologi mengarah pada usaha untuk mengklasifikasikan, mengkelaskan, mengelompokkan objek berdasarkan aspekaspek/kaidah-kaidah tertentu (Antariksa,
2010). Studi pengelompokkan ini telah pernah dilakukan oleh sebuah organisasi dari Belanda dimana membagi kawasan pusat kota menjadi beberapa kelompok sesuai dengan fungsi dan image Kota. Beberapa kelompok tersebut yaitu Kawasan Industri dan perkantoran, kawasan pemukiman buruh, kawasan rumah sakit dan kawasan perdagangan (Dun, Peter. Corten, Jean Paul. Tjakradma, 2004). Hingga saat ini tidak ada perubahan struktur Kota yang cukup berarti sehingga merubah wajah Kota. "Image" yang telah terbentuk sangat mudah dipahami secara visual.

Peruntukkan kawasan atau "zoning" kota yang sangat tertata. Dan beberapa kawasan sangat sesuai dengan posisi geografi dan fungsinya. Kawasan tersebut seperti kawasan pusat perkantoran, kawasan pemukiman, kawasan perdagangan, kawasan rumah sakit, kawasan transportasi batubara serta kawasan pemerintahan. Keseluruhan peruntukkan kawasan ini terhubung dengan sirkulasi yang baik dengan skala kota yang sangat manusiawi, sehingga penghuni kota ini terlihat sangat akrab antara satu dengan lainnya. Hingga saat ini struktur pembentuk tersebut masih sedia kala dan belum terdapatnya rencana dari Pemerintah kota untuk merubahnya. Diperkirakan pembangunan kota industri tambang ini berkisar tahun 1890 hingga tahun 1930. Hal ini terlihat dari foto-foto lama koleksi Pemerintah Kota dan koleksi dari KITLV Belanda.

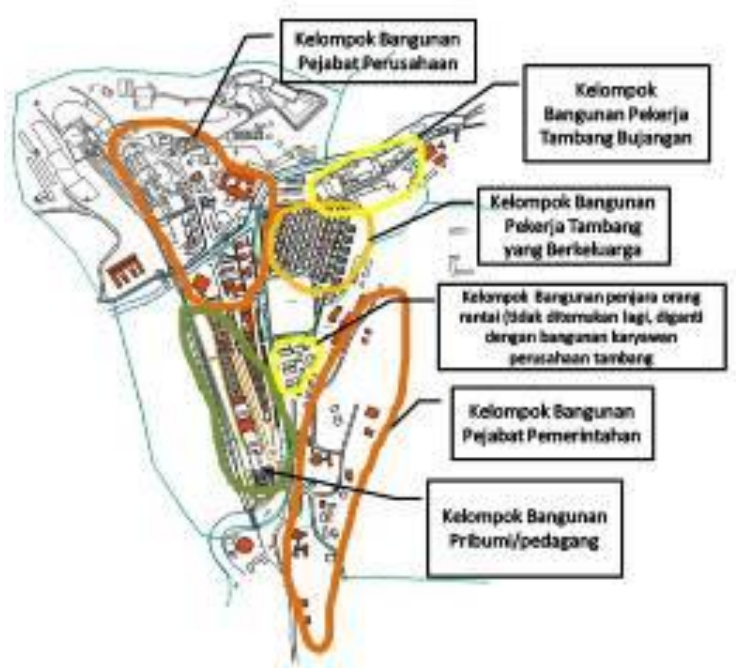

Gambar 2. Kelompok fungsibangunan menurut ta ta letak,sumber a nalisa tim peneliti. 
Sehingga periode ini termasuk kepada periode akhir dari "Empire style" dan awal dari munculnya "Indisch architecture". Dari periode arsitektur kolonial ini, tidak ditemukan peninggalan dengan ciri-ciri "Empire style", berkemungkinan besar karena fungsi kota ini adalah kota yang akan dibangun untuk kota tambang batubara, sehingga Pemerintah kolonial tidak begitu menginginkan membaw a budaya Belanda ke kota ini. Namun ciri-ciri dari "Indisch architecture" sangat terlihat karena banyaknya bangunan menggunakan elemen-elemen vernacular dan diselaraskan dengan teori thermal. Hal ini ditandai banyaknya bangunan yang memiliki atap tinggi, jurai yang lebar, jendela dan pintu yang lebar dan tinggi, plafon yang tinggi dan teras depan. Dengan struktur bangunan demikian, sangat membantu kenyamanan manusiav berada didalam bangunan tersebut mengigat suhu udara $34^{\circ} \mathrm{C}$ pada siang hari dan $24^{\circ} \mathrm{C}$ pada malam hari. Pada gambar 02 diketahui bahwa hampir $90 \%$ dari seluruh peninggalan kota industry tambang ini masih cukup terpelihara, kemungkinan besar karena asset ini dimiliki oleh perusahaan negara yaitu PT Bukit Asam dan PT KAI. Perubahan asset negara tentu akan membutuhkan biaya dan administrasi yang rumit. Sehingga bangunan tua ini masih dipergunakan seperti apa adanya. Kondisi ini sangat menguntungkan kepada usaha pelestarian bangunan dan kota. Penetapan zonasi di Kawasan Kota Lama Tambang Batubara Sawahlunto dilakukan berdasarkan pada kriteria yang melekat di kawasan ini yaitu: 1 . Situs atau kawasan yang telah ditetapkan sebagai cagar budaya; 2 . Situs atau kawasan rawan ancaman yang disebabkan faktor alam maupun manusia; 3. Situs atau kawasan yang mempunyai potensi pengembangan dan pemanfaatan, serta; 4. Situs atau kawasan yang memerlukan pengelolaan khusus. (Pemerintah Kota Sawahlunto, 2019)

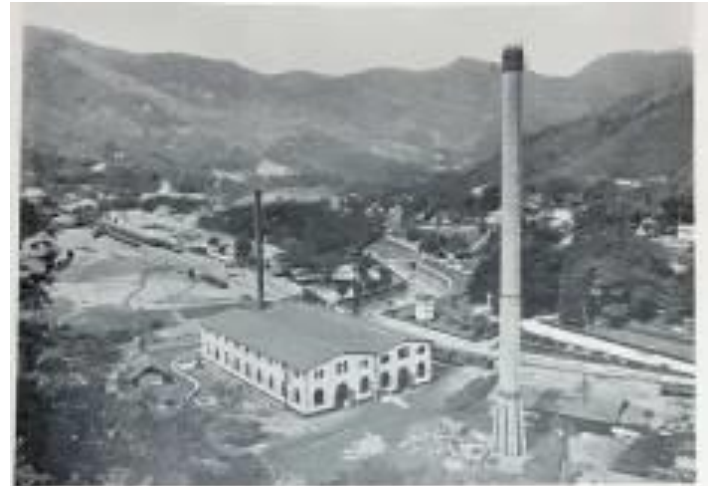

Gambar 3. Foto lama Kota sawahlunto tahun 1930 (Cheris, 2009b)

Pada poin nomor 2 dan nomor 3 diatas merupakan dasar yang cukup kuat untuk mengawali riset ini. Perlunya mempelajari bentuk-bentuk arsitektur kota industry pada masa kolonial juga akan menambah wawasan dalam melanjutkan analisa riset kali ini. Tinjauan beberapa foto lama pertambangan milik kolonila Belanda dari beberapa buku menunjukkan tipologi arsitekur yang serupa yaitu sangat merespon keadaan iklim setempat.

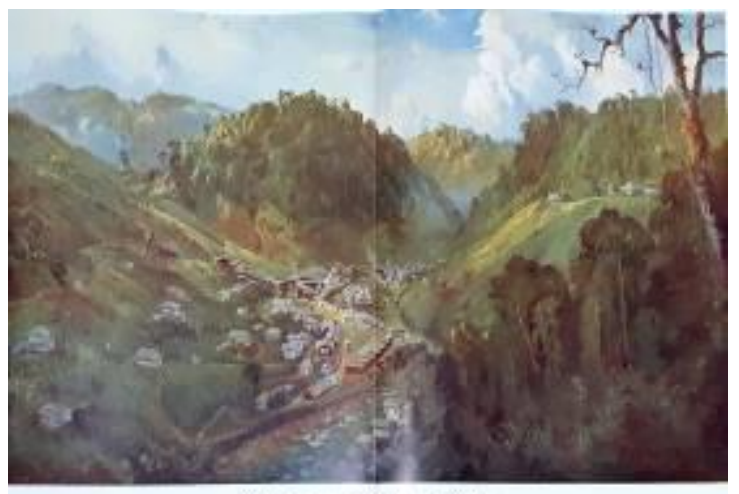

Gambar 4. Lukisan tambang emas di Simau rejang lebong, Bengkulu (Ligthart, Hovig, 1926)

Terdapat beberapa kota tambang besar yang ada di Indonesia seperti beberapa foto dibawah ini. Dari lukisan dan foto diatas bisa terlihat dengan jelas bahwa penggunaan atap pelana menjadi tipologi arsitektur yang dominan terhadap beberapa pabrik yang dibangun oleh kolonial Belanda. 


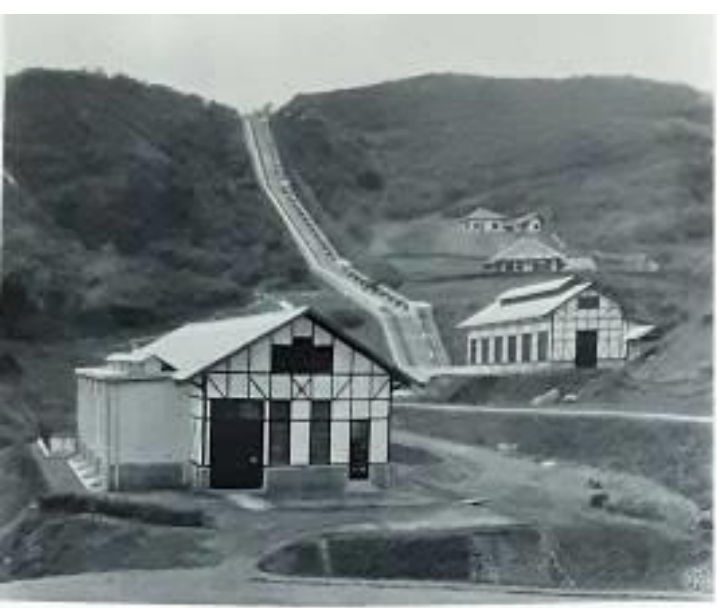

Gambar 5.Pembangkit listrik Plengan Bandung (Ligthart, Hovig, 1926)

Dalam pemilihan bangunan yang akan diriset kali ini menggunakan metoda yang sering dipakai oleh seorang perancang. Metode tersebut yaitu metode form follow function (LESLIE, 2010)

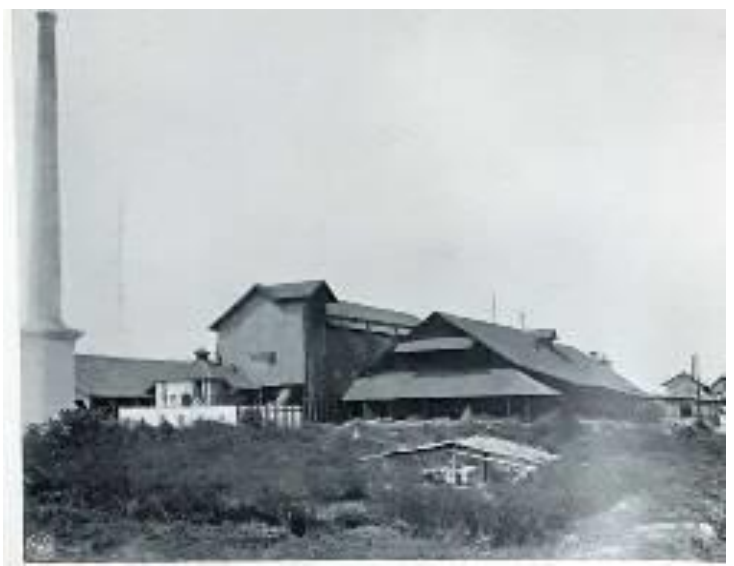

Gambar 6. Pabrik Pengolahan Biji Timah Belitung(Ligthart, Hovig, 1926)

Metode form follow function yaitu bentuk mengikuti fungsi, dimana perancang mengutamakan fungsi kemudian mendisain bentuk yang sesuai dengan fungsi tersebut. Metode ini lebih manusiawi karena keinginan pengguna bangunan akan dipenuhi oleh siperancang. Metode function follow form yaitu sebuah metode perancangan yang memaksa pengguna bangunan harus menyesuaikan diri dengan bentuk bangunan yang sudah ada walaupun tidak sesuai dengan keinginan dan kebutuhan mereka. Apabila kita amati bangunan-bangunan yang terdapat di kota ini, sepertinya kuat kecendrungan menggunakan metoda form follow function. Metoda ini dinilai lebih adaptive dengan lingkungan sekitarnya. Terlihat jelas bahwa penyesuaian dimensi, ketinggian serta luas bangunan pada tapak cukup apik. Tema arsitektur juga tidak terlalu berbeda antara satu dengan yang lain bangunan, namun terlihat cukup serasi dan harmonis pada tapak dimana bangunan tersebut didirikan. Melalui metoda ini, tim telah memilih 11 (sebelas bangunan) dengan fungsi berbeda dan kawasan yang berbeda, namun memiliki kesamaan terhadap tema yaitu menyesuaikan iklim tropis dengan dinding dan plafon yang tinggi, jendela yang besar dan atap yang tinggi.

Menurut hasil penelitian Ashfa (2007) karakter visual suatu bangunan pada umumnya dapat diidentifikasi melalui: 1. Fasade; 2 . Warna; 3. Tekstur; 4. Material; 5. Tipe Jendela; dan 6. Atap. Handinoto (1996: 187-191) mengemukakan bahwa suatu bangunan kolonial memiliki karakteristik tersendiri, antara lain: 1. Bentuk denah yang "tipis" untuk memudahkan penghawaan silang; 2 . Orientasi bangunan yang tepat terhadap sinar matahari; 3. Galeri keliling bangunan yang melindungi dari tampias hujan dan sinar matahari langsung; 4. Lubang ventilasi diperlihatkan sebagai elemen arsitektur yang menarik; 5 . Penataan massa bangunan memiliki jarak agar orang menikmati keseluruhan bangunan; dan 6. Tampak yang berbentuk simetri untuk menambah kesan monumental bangunan. (Antariksa, no date).

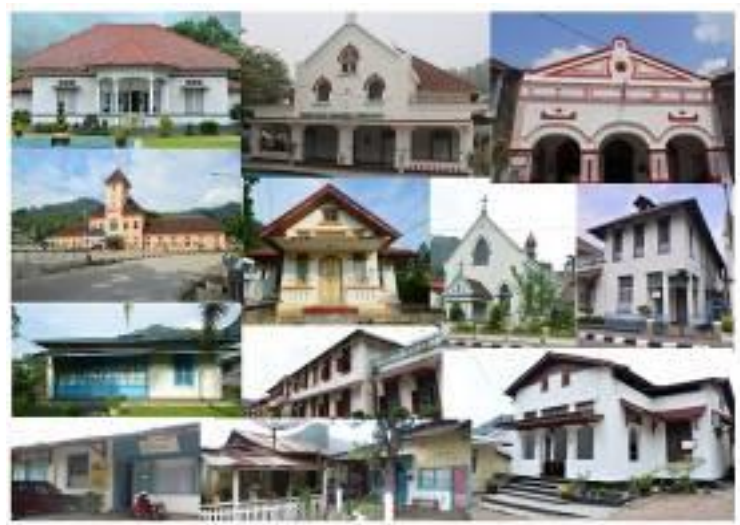

Gambar 7. Studikasus Sumber (Gino, 2019) 
Pada gambar 7, didapati beberapa jenis bangunan yang akan dianalisa dan akan didokumentasikan terutama mengenai elemen arsitektur. Bangunan tersebut adalah:

1. A5.1.a. Head Office of Ombilin Mining Enterprise

2. A5.1.g. Engineer Resident W-14

3. A5.2.a. Tangsi Tanah Lapang (terdapat 3 tipe)

4. A5.4.b. Pek Sin Kek House

5. A5.5.b. Assembly Hall

6. A5.5.d. Santa Barbara Catholic Church

7. A5.5.e. Santa Lucia School

8. A5.5.f. Santa Barbara Convent

9. A5.5.j. House of Court Clert

10.A5.5.i. House of State Attorney

11.A5.5.k. House of The Municipal Government official 1.

Jenis penomoran bangunan pada peneltian kali ini menggunakan penomoran atribut bangunan dari UNESCO, agar memudahkan dalam klarisikasi dan memudahkan untuk dimasukkan kedalam database keseluruhan.

Untuk elemen bangunan yang menjadi pembentuk karakter bangunan tersebut sesuai dengan teori diatas adalah: dinding Depan (fasadé), pintu, jendela, gable, ventilasi, tiang, atap, kanopi, teras, dan ornamen/ukiran. Penggunaan bentuk, ukuran, gaya sangat ditentukan oleh fungsi bangunan itu sendiri. Semakin besar ruang akan membutuhkan ukuran jendela yang besar. Begitu juga sebaliknya, ruang yang kecil akan membutuhkan jendela yang kecil juga.

\subsection{Fasade}

Pembangunan kota ini diawali pada permulaan abad ke 20. Dengan begitu jenis arsitektur yang digunakan pada waktu itu adalah arsitektur indisch. Kebanyakan dari bentuk fasade ini masih sedia kala ketika pembangunan pertama. Adapun perubahan yang terlihat dengan data awal yang ditemui pada dokumen data base milik Pemerintah, bisa di buktikan dan terdapat rekamannya. Perubahan juga terjadi pada kelompok bangunan hunian masyarakat. Hal tersebut disebabkan karena kebutuhan pembangunan garase kendaraan. Namun perubahan tersebut tidak signifikan mempengaruhi bentuk tampilan depan bangunan.

\subsection{Warna}

Elemen berikutnya yang mempengaruhi tambilan bangunan adalah warna. Belum ada penelitian yang lebih dalam terhadapa pencarian data awal sekali mengenai warna. Penelitian mendapatkan data warna awal ini sebaiknya menggunakan seorang arkeolog. Namun analisa warna bisa dimulai dari warna yang pernah terlihat dari awal pemugaran bangunan-bangunan tersebut. Pada kebanyakan warna bangunan tersebut menggunakan warna putih untuk dinding dan warna kayu (warna coklat) untuk ventilasi dan jendela. Sedangkan untuk ornamen disesuaikan dengan warna kusen pintu dan jendela. Menurut informasi yang diterima tim peneliti bahwa, kebijakan penggunaan warna tidak begitu ditekankan oleh Pemerintah. Namun warna-warna yang terlihat pada dinding bangunan kebanyakan menggunakan warna putih. Sedangkan untuk bangunan kantor PT Bukit Asam, untuk saat ini sudah dikembalikan ke warna semula yaitu warna putih.

\subsection{Tekstur}

Hampir seluruh bangunan memiliki tekstur dinding dan kayu yang sama. Kemungkinan karena tahun pembangunanya yang beriringan. Bahan materialpun didatangkan dari luar kota tambang ini. Untuk dinding memiliki lapisan plester batu kapur yang kasar namun kuat. Sedangkan tekstur pekerjaan kayu juga cukup halus dan mempunyai nilai estetika.

\subsection{Material}

Material bangunan sangat ditentukan oleh teknologi yang sudah ada pada saat diawalinya pembangunan infrastruktur Kota sekitar akhir tahun 1900. Pada saat itu pabrik semen indarung di Kota Padang sudah dieksplorasi oleh Pemerintah Belanda sehingga penggunaan semen telah dipakai pada seluruh pembangunan infrastruktur di Kota Sawahlunto.

Untuk material batubata didatangkan dari Kota Bukittinggi karena di Kota tersebut telah terdapat industri Batu Bata tradisional yang dikelola oleh pribumi. Sedangkan untuk material Seng, Baja, dan Besi masih diimport dari Belanda. Belum ada penelitian yang pasti tentang jenis besi, baja yang digunakan pada saat itu, namun pada sebagian infrastruktur 
yang ditemui, terdapat merek merek yang bertuliskan Bahasa belanda dan jerman. Sedangkan penggunaan material kayu, ratarata diambil dari hutan tropis di daerah Sumatera Barat, dimana terdapat beberapa jenis kayu yang digunakan, yaitu kayu Banio dan kayu Rasak yang mana merupakan kayu kelas 1 (satu) dengan mutu yang sangat terbaik.

Sebagian besar bangunan masih menggunakan batu kapur sebagai material pokok untuk bahan plester disamping semen indarung. Kemungkinan besar karena harga yang murah, kemudian adanya keahlian tukang pribumi dalam penggunaannya juga ketahanan yang cukup tinggi. Kelemahan dari batu kapur ini adalah menyimpan air. Oleh sebab itu, struktur bangunan dirancang lebih tinggi dari tanah. Sebagian besar bangunan memperlihatkan setengah dari pasangan pondasi batukali diatas tanah. Kemudian baru adanya pemasangan dinding batu bata. Dari keadaan tersebut bisa dipastikan pasangan pondasi yang terlihat diatas permukaan tananh merupakan teknik perlindungan terhadap dinding batu bata dan plesteran batu kapur. Sehingga kelembaban terhadap air pada dinding bisa diminimalisir dengan teknik tersebut. Teknik ini memang telah terbukti dengan masih berdirinya bangunan-bangunan peninggalan kolonial yang berumur lebih dari serratus tahun.

\subsection{Tipe Jendela}

Terdapat beberapa tipe jendela, diantaranya jendela dengan dua lapis, lapisan pertama adalah kaca dengan bukaan kedalam $180^{\circ}$, dan lapisan kedua menggunakan kayu dengan bukaan keluar $180^{\circ}$. Hampir semua jendela memiliki vetilasi. Ventilasi tersebut juga terdapat dua jenis, ventilasi dengan penutup dari kaca yang bisa dibuka, dan ventilasi dengan kayu yang disusun secara vertikal. Ventilasi ini sangat bermanfaat untuk sirkulasi udara dan pencahayaan matahari.

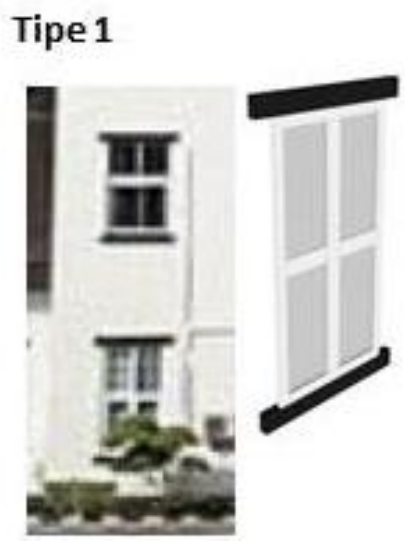

Gambar 8. Tipe 1, dengan bukaan keatas.

Jenis Jendela satu lapis dan bukaan vertical keatas dengan penahan daun jendela. Diperkirakan bentuk ini diadopsi dari negri Belanda. Gedung ini berfungsi sebagai Kantor Pusat PT. Bukit Asam.

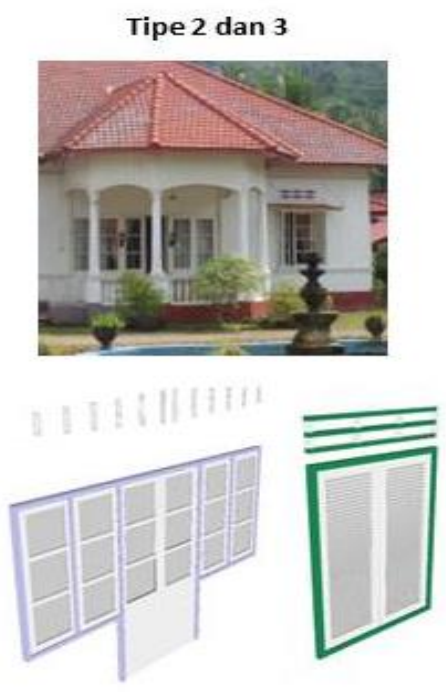

Gambar 9. Tipe 2 da n Tipe 3 padasa tu bangunan.

Pada Tipe 2 ini, daun jendela terdiri dari 2 lapis, lapir pertama double dengan panel kaca dan bukaan $180^{\circ}$ kedalam ruangang, dan lapis kedua berupa panel jalusi dengan bukaan $180^{\circ}$ keluar bangunan. Sedangkan tipe tiga adalah pintu masuk yang serangkai dengan jendela. Daun pintu berupa setengah kaca dan setengah panel kayu. Daun pintu sepertinya telah mengalami perubahan material. 

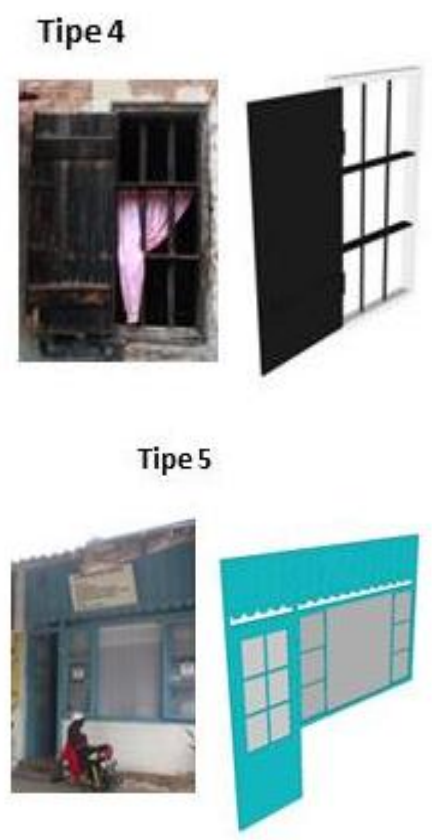

Tipe 6

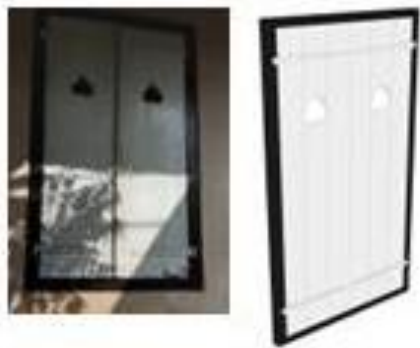

Gambar 10. Tipe 4,5,6 pada bangunan pemukiman.

Gambar 10 adalah tipe-tipe jendela pada permukiman penduduk, Tipe 4 merupakan tipe yang paling sederhana tanpa kaca, hanya teralis dari kayu dan daun penutup jendela. Tipe ini ditemukan pada bangunan bekas penjara orang rantai. Tipe 5 telah mengalami perubahan, namun masih pola yang lama tanpa merubah ukuran jendela. Perubahan pada jendela asli dengan kawat harmoni, kemudian diganti dengan kaca. Sedangkan tipe 6 dengan ukuran yang cukup besar, tanpa kaca, dan daun penutup jendela.

Tipe 9 terletak pada gereja Santa Barbara, dengan daun jendela satu lapis panel kaca dan dibuka $180^{\circ}$. Terdapat dua ukuran dengan bentuk yang sama. Bentuk lain yaitu yang terletak pada gable dengan panel jalusi.

Tipe 10 dan 11 terletak pada bangunan yang berdekatan, yaitu sekolah Santa Lucia dan
Asrama Biarawati. Kedua bangunan ini terpisah, namun memiliki bentuk jendela yang hampir sama.

\section{Tipe 9}

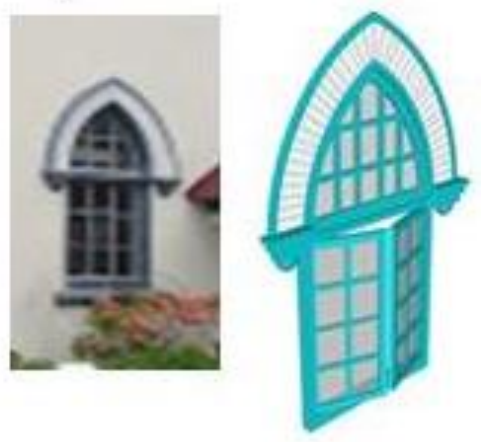

Gambar 11. Tipe 9 pada Gereja Santa Barbara.

Perbedaan terletak pada penempatan, tipe 10 pada bangunan lantai 1 dan tipe 11 terletak pada lantai 2. Kedua jenis jendela ini hanya memiliki daun jendela dengan panel jalusi dan teralis kayu, sedangkan untuk ventilasi bisa dibu $45^{\circ}$ kearah luar bangunan dengan panel kaca. Bentuk ini masih bertahan hingga saat ini.

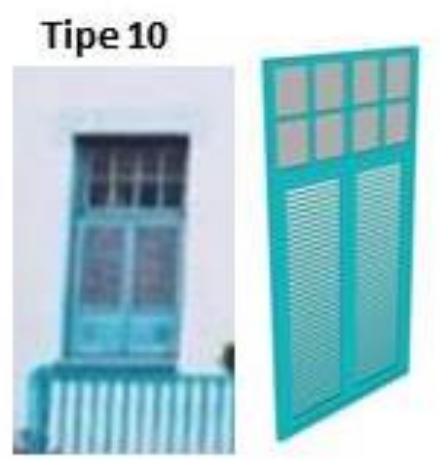

Tipe 11

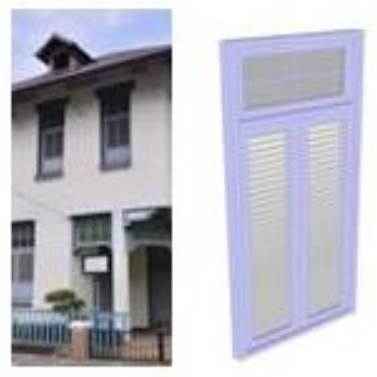

Gambar 12. Tipe 10 dan 11 pada Sekolah Santa Lucia dan Asrama Biarawati. 
Pada bangunan bekas Kepala Kejaksaan ini ditemukan teras yang cukup luas dengan ventilasi dari kaca dan daun pintu serta daun jendela dengan ukuran besar.

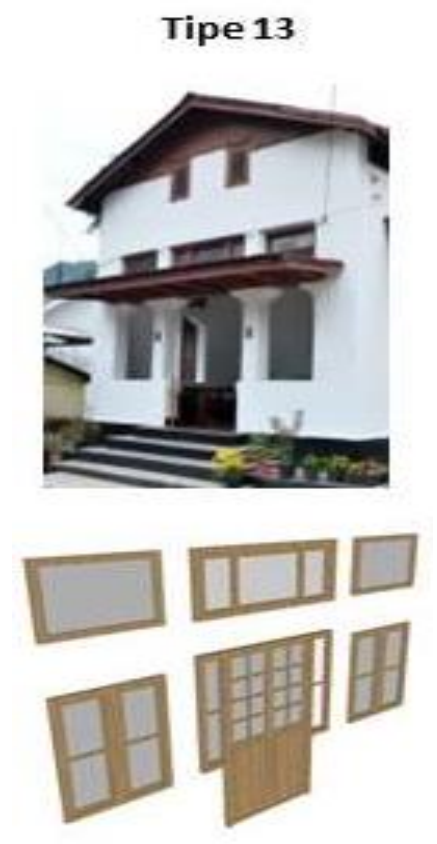

Gambar 13. Tipe 13 pada bangunan bekas Rumah Kepala Kejaksaan.

Kemungkinan besar karena disesuaikan dengan ukuran rumah yang tinggi dan luas. Daun jendela terdiri dari dua lapis juga, lapispertama menggunakan panel kaca dengan bukaan $180^{\circ}$ kedalam dan lapis kedua dengan panel jalusi dengan bukaan keluar bangunan.

Bentuk dari pintu masuk utama sebagian besar berupa pintu panel kayu. Material pintu kayu yang ditemukan kebanyakan dari kayu rasak, dimana kayu ini memiliki kadar minyak yang tinggi, sehingga hampir sebagian besar pintu panel tersebut masih asli dan belum terkena rayap.

Pintu panel tersebut merupakan pintu panel ganda dengan dua lembar kayu yang besarbesar, pintu jenis ini lebih tahan pada pemakaian dibanding pintu panel tunggal. Terdapat juga pintu panel tunggal yang banyak di gunakan pada pintu kamar agar lebih efektif dan efisien. Sedangkan pintu lainnya yaitu terbuat dari lembaran-lembaran kayu yang disusun secara vertikal.

Terdapat juga pintu kayu dengan menggunakan jenis susunan jalusi, diperkirakan cuaca yang panas pada siang hari akan lebih ringan apabila menggunakan pintu dari susunan jalusi agar memudahkan udara masuk kedalam ruangan.Namun akibat dimakan usia, hanya sedikit sekali bentuk asli dari pintu masuk yang masih bisa kami temui. Salah satunya adalah sebuah pintu besar milik bangunan Fek Sin Kek, yang masih kokoh dan masih asli. Seperti gambar dibawah ini.
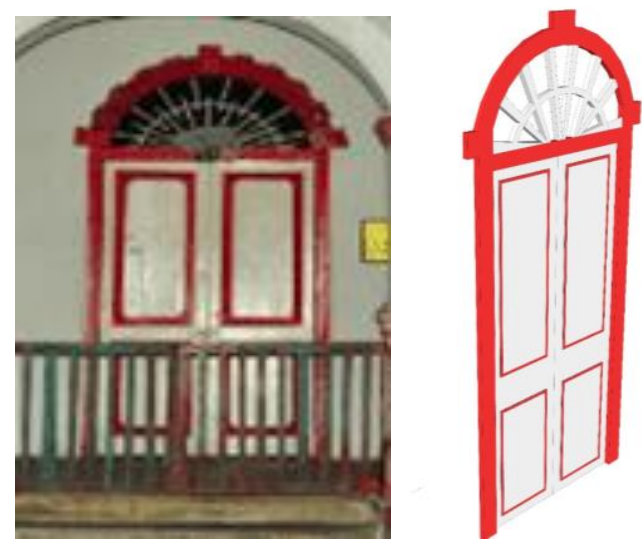

Gambar 14. Daun Pintu yang masih a sli.

Sedangkan pada bagian depan bangunan terdapat teras dengan pembatas dinding seukuran $\pm 1,20 \mathrm{M}$ serta tiang sebagai konstruksi teras hingga plafon untuk menciptakan kesan privasi. Sementara untuk menambah cahaya masuk kedalam ruangan, maka terdapat ventilasi dengan bentuk empat persegi dengan penutup kaca dalam bentuk ayunan (swing) agar bisa dibuka.

\subsection{Atap}

Dari sebanyak 12 buah bangunan sebagai objek riset kali ini, ditemukan lima jenis bentuk atap. Pada umumnya terdapat dua jenis tipologi atap, yaitu atap pelana dan atap perisai. Penggunaak atap pelan memiliki beberapa keuntungan seperti, pengerjaan yang mudah, efisien dan sebagai sirkulasi udara didalam bangunan. Udara yang panas didalam bangunan akan dikeluarkan pada dinding atap pelana yang juga berfungsi sebagai penopang atap. Sehingga seringa kita melihat beberapa bentuk Lobang sejenis batu roster atau dibuat langsung pada puncak dari dinding tersebut.

Karena penggunaan atap pelana mengharuskan adanya dinding segitiga yang akan menjadi pemikul beban atap yang disebut dengan 
gable/gevel sekaligus berfungsi sebagai penutupnya.

Pada bangunan yang menggunakan atap perisai ditemukan jurai yang menjorok keluar bangunan dengan panjang maksimal 1 meter. Namun ada juga yang tidak menggunakan jurai. Hal ini juga sangat tergantung kembali kepada fungsi bangunan.

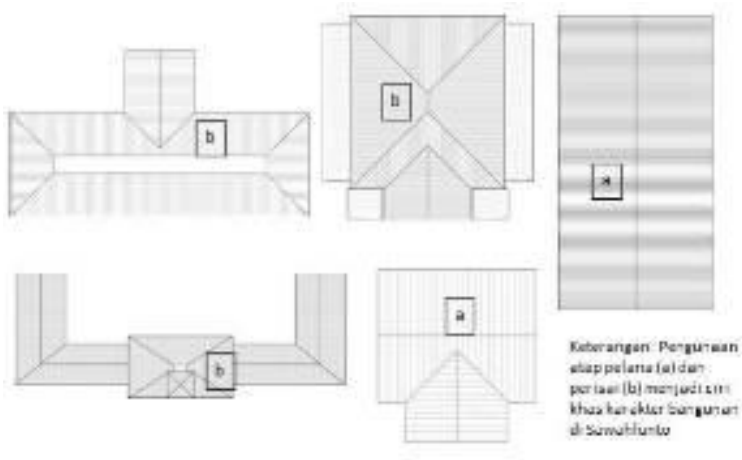

Gambar 12. Beberapa bentuk tipologia tap yang banyak ditemui

Penggunaan atap perisai yang tidak menggunakan jurai diutamakan untuk penggunaan bangunan kantor dan bangunan sosial. Hal tersebut dilakukan kemungkinan besar untuk menonjolkan ketinggian dinding serta ornamen yang menghiasinya.

\subsection{Gabel/gevel}

Banyak yang berpendapat penggunaan Gable/gevel adalah pengaruh dari arsitektur Belanda. Namun pada hakekatnya bangunan tradisional seperti rumah Minangkabau dengan atap gonjong juga menggunakan gable berbentuk segitiga sebagai pemikul rangka atap dan sekaligus penutup dinding pada atap. Beberapa gable yang digunakan ini juga memiliki ukiran yang menembus dinding, sehingga juga berfungsi untuk sirkulasi udara ketika suhu panas. Sedangkan Gable/gevel yang terdapat paada bangunan kolonial di Kota Sawahlunto merupakan peninggalan kolonial dimana dinding yang berbentuk segitiga ini penuh dengan ornamen-ornamen. Terdapat beberapa jenis Gable/gevel pada bangunan di Kota Sawahlunto yaitu Atap pelana dengan tambahan atap serambi (gable roof with shed roof addition) pada gambar (a), Atap pelana depan (front gable) gambar (d) dan (c) dan A tap pelana kotak (box gable roof) pada gambar (b).
Penamaan Gable/gevel itu sendiri berasal dari bahasa Belanda.

Di Negri Belanda sendiri gable didisain sedemikian rupa sehingga menghasilkan salah satu estetika bangunan, disamping terdapat fungsi lain dibalik dinding Gable/gevel tersebut. Namun pada bangunan yang sedang di riset ini, fungsi Gable/gevel adalah untuk sirkulasi udara dan estetika bangunan.

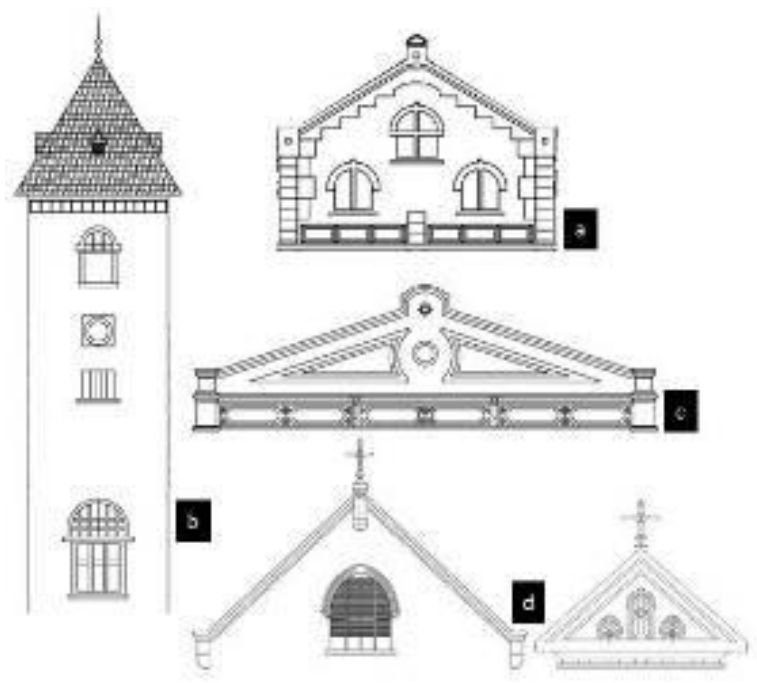

Gambar 13. Beberapa bentuk gable/ gevel pa da beberapa bangunan dengan beberapa fungsi bangunan.

Walaupun gable/gevel lebih dikenal di Negri Belanda, namun telah menyumban gkan estetika bangunan indiche di Negri kita. Sehingga perlu mendapat pertimbangan untuk sela lu dilestarikan.

\subsection{Roster}

Pada gambar 03 terlihat beberapa roster yang digunakan pada dinding pemikul atap pelana. Bentuk, disain dan ukurannya ditentukan sesuai dengan keharmonisasian bangunan. Pada gable juga terdapat roster tersebut yang disesuaikan dengan estetika gable tersebut. Roster yang dibahas kali ini adalah roster yang terdapat pada dinding pemikul atap pada bangunan dengan nomor registrasi A5.2.a. Tangsi Tanah Lapang dan jua terdapat pada rumah di tangsi baru.

Salah satu fungsi roster tersebut adalah untuk sirkulasi udara. Penggunaan roster ini sangat dibutuhkan untuk bangunan di Kota ini karena iklim yang cukup panas hingga 36 derajat Celsius. Pada riset kali ini hanya 2 jenis roster 
yang bisa diidentifikasi, untuk bangunan yang berlokasi pada kawasan perumahan Tanah Lapang dan pemukiman Tangsi Baru.
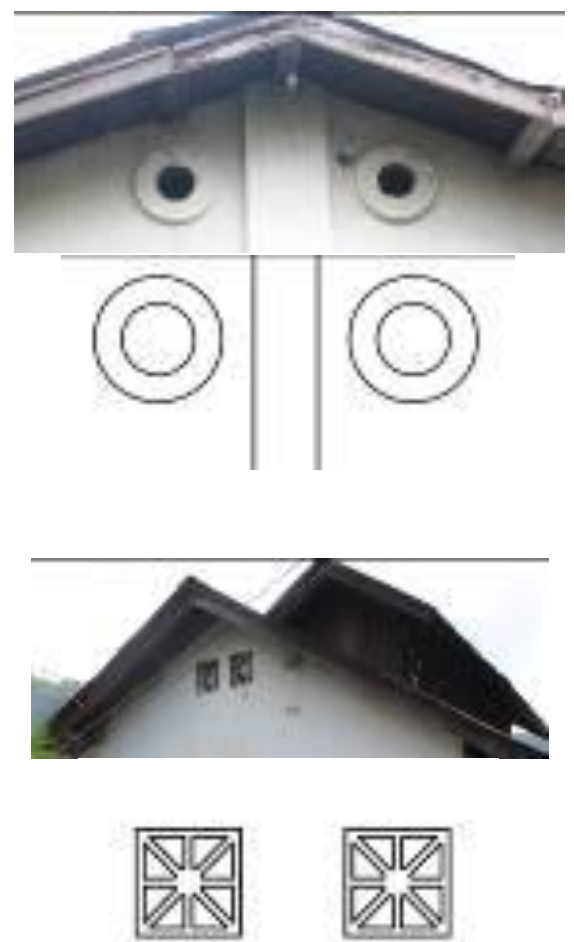

Gambar 14. Beberapa bentuk roster pada dinding gengan atap pelana

\section{KESIMPILAN}

Pada riset kali ini telah didokumentasikan beberapa elemen bangunan mulai dari fasade, tekstur, material, bentuk jendela, pintu, ventilasi, tipologi atap, gable dan roster dari 11 (sebelas) buah bangunan yang terdapat di Kota Sawahlunto. Dengan keterbatasan waktu dan dana penelitian semoga riset ini akan bisa diselesaikan pada riset selanjutnya mengingat masih banyaknya bangunan yang belum terdokumentasikan. Namun untuk tahap ini hasil dokumentasi elemen bangunan ini sudah bisa dijadikan pedoman untuk pemugaran bangunan di Kota Sawahlunto hingga dibuatkannya dokumen yang lebih rinci.

\section{UCAPAN TERIMAKASIH}

Penelitian ini dilakukan atas dukungan pendanaan dari LPPM Universitas Lancang Kuning. Ucapan terima kasih juga ditujukan kepada Pemerintah Kota Sawahlunto dalam hal ini Kantor Kebudayaan yang telah banyak membantu terselenggaranya penelitian ini, sehingga bias terlaksana.

\section{REFERENSI}

Antariksa (2010) 'Pendekatan DeskriptifEksploratif Dalam Pelestarian Arsitektur Bangunan Kolonial Di Kawasan Pecinan Kota Pasuruan', in Seminar Nasional "Metodologi Riset dalam Arsitektur.

Antariksa (no date) 'Beberapa Teori Dalam Pelestarian Bangunan', academi.edu.

Cheris, R. (2009a) The Picture of Mining Town of Sawahlunto In The Past. I. Sawahlunto West Sumatera: Pemerintah Sawahlunto.

Cheris, R. (2009b) The Picture of Mining Town of Sawahlunto In The Past. 1st edn. Sawahlunto Goverment.

Cheris, R. (2014) 'Perencanaan Konservasi Kawasan Eks Permukiman Buruh Tambang Batubara di Kota Sawahlunto', Arsitektur Melayu dan Lingkungan, I(2).

Cheris, R. (2020) 'Sustainable Conservation of the Coal Mining Town: Ombilin Sawahlunto West Sumatra Indonesia Context', IOP Publishing, 469(012068). doi: 10.1088/1755-1315/469/1/012068.

Dun, Peter. Corten, Jean Paul. Tjakradma, I. (2004) 'MIners, migrants and monuments- Transformation and conservation of a Mining Town', PUM, (32046 M IA).

Gino, R. S. G. \& T. (2019) Cagar Budaya Kota Sawahlunto. I. Edited by A. W. Sarwo. Bandung: ITB Press.

LESLIE, T. (2010) 'Dankmar Adler's Response to Louis Sullivan's “"The Tall Office Building Artistically Considered"': Architecture and the "'Four Causes"”, Journal of Architectural Education, pp. 83-93. Available at: https://www.researchgate.net/publicatio 
n/229483190_Dankmar_Adler's_Respo nse_to_Louis_Sullivan's_The_Tall_Offi ce_Building_Artistically_Considered_A rchitecture_and_the_Four_Causes.

Ligthart, Hovig, R. (1926) The Indische Bodem. 1st edn. Weltevreden: Drukkerij Volkslectuur.

Pemerintah Kota Sawahlunto (2019) PENETAPAN ZONASI KAWASAN CAGAR BUDAYA NASIONAL KOTA LAMA TAMBANG BATUBARA SAWAHLUNTO. Indonesia.

Yetti, A. E. \& T. A. F. \& I. P. (2020) 'Pengaruh Perubahan Fungsi Terhadap Tipologi Arsitektur Fasad Bangunan di Kampung Wisata Prawirotaman', arsitektura, 18(1 April 2020), pp. 5362. 